\title{
Desigualdades e subjetividade: construção da práxis no contexto da pandemia de covid-19 em território vulnerável'
}

\section{Inequalities and subjectivity: construction of praxis in the context of the Covid-19 pandemic in vulnerable territory}

\section{Carlos Roberto de Castro-Silva ${ }^{a}$ \\ (D) https://orcid.org/0000-0002-8880-1042 \\ E-mail: carobert3ळhotmail.com}

Aurea Iannib

(iD) https://orcid.org/0000-0003-1366-8651

E-mail: aureanniळusp.br

\section{Elaine Forte ${ }^{c}$}

(i) https://orcid.org/0000-0002-6042-5006

E-mail: elainecnforteœgmail.com

anniversidade Federal de São Paulo- Instituto Saúde e Sociedade. Departamento de Políticas Públicas e Saúde Coletiva. Santos, São Paulo, Brasil.

bUniversidade de São Paulo. Faculdade de Saúde Pública. Departamento de Política, Gestão e Saúde. São Paulo, Brasil.

'Universidade Federal de Santa Catarina, Centro de Ciências da Saúde, Departamento de Enfermagem, Florianópolis, Brasil.

\section{Correspondência}

Carlos Roberto de Castro-Silva

Av. Ana Costa, 438, ap. 7I. Santos, SP, Brasil. CEP $11060-002$.

\section{Resumo}

A questão da desigualdade social tem sido objeto de muitos estudos que buscam compreender como a dirimir na construção de sociedades mais justas. A pandemia de covid-19 acirrou situações de pobreza e violência vivenciadas pela população excluída de seus direitos. A complexidade da questão estudada exige a abertura de frentes de conhecimento interdisciplinares. Nesta perspectiva, os estudos sobre a afetividade no campo da psicologia sócio-histórica têm fortalecido o papel da subjetividade nos estudos sobre processos dialéticos de inclusão e exclusão social. O objetivo deste dossiê é buscar interpretações possíveis sobre a relação entre saúde e sociedade, visando construir subsídios para a implementação de políticas públicas. Desde 2012 têm sido desenvolvidos estudos, balizados principalmente na pesquisa participante, que consideram as práticas da atenção primária à saúde como desencadeadoras de temas associados ao processo saúde-doença-cuidado em território vulnerável de Cubatão. A hermenêutica de profundidade tem sido a principal referência de análise, que dialoga com o com a epistemologia qualitativa. Os artigos apresentados neste dossiê trazem ricas experiências e reflexões: cuidado em território de exclusão social e interseccional; participação social de lideranças comunitárias neste contexto; vivências da violência em território vulnerável.

Palavras-chave: Desigualdade Social; Afetividade; Atenção Primária à Saúde; Covid-19; Hermenêutica.

\footnotetext{
1 Os estudos contidos neste dossiê são um desdobramento das pesquisas "Ética do cuidado e construção de direitos: acolhimento psicossocial em práticas da saúde da família em situações de exclusão social” (fomentada pela Fundação de Amparo à Pesquisa do Estado de São Paulo (Fapesp), n 2016/23973-2), "Desigualdade social e subjetividade: trajetórias de vida e lutas por melhores condições de vida e saúde em território vulnerável da Baixada Santista” (apoiada pelo Conselho Nacional de Desenvolvimento Científico e Tecnológico (CNPq), $n^{0}$ 407836/2016-o), que foram aprovadas pelo Comitê de Ética em Pesquisa da Universidade Federal de São Paulo, pareceres 2.198.202 e 2.047.444, e "Ética do cuidado e processos psicossociais de participação social em práticas da saúde da família em situações de exclusão social" (Bolsa Produtividade CNPq n $\left.{ }^{0} 308730 / 2019-4\right)$.
} 


\section{Introdução}

Social inequality has been subject of many studies that seek to understand how to address it in the construction of more equal societies. The Covid-19 pandemic aggravated situations of poverty and violence experienced by the population deprived of their rights. The complexity of this issue requires the opening of interdisciplinary knowledge subjects. In this perspective, studies on affectivity in the field of socio-historical psychology have strengthened the role of subjectivity in studies on dialectical processes of social inclusion and exclusion. The objective of this dossier is to seek possible interpretations on the relationship between health and society, aiming to build subsidies for the implementation of public policies. Since 2012, studies that consider the practices of Primary Health Care as triggering themes associated with the health-disease-care process has been conducted in the vulnerable territory of Cubatão, state of São Paulo, Brazil. Participatory research has been the main marker of studies conducted in this territory. Depth hermeneutics has been the main reference for analysis, which dialogues with qualitative epistemology. The articles presented in this dossier bring a wealth of experiences and reflections: care in a territory of social and intersectional exclusion; social participation of community leaders in this context; experiences of violence in vulnerable territory.

Keywords: Social inequality; Affectivity; Primary Health Care; Covid-19; Hermeneutics.
A questão da desigualdade social tem sido objeto de muitos estudos que buscam compreender como a dirimir na construção de sociedades mais justas, especialmente em países do Cone Sul. A cidadania e os direitos básicos ficam comprometidos em situações de exclusão social, sustentando um ciclo perverso de precariedade do modo de vida das pessoas e das comunidades, em termos de alimentação, moradia, educação, saúde, emprego, lazer, entre outras (Dussel, 200o; Souza, 2004).

No último dia de 2019, a China relatou as primeiras ocorrências de contaminação pelo novo coronavírus Sars-Cov-2 -, cuja incidência aumentou em proporções exponenciais já nas primeiras semanas do ano seguinte. Em 30 de janeiro de 2020, a Organização Mundial da Saúde declarou que o surto provocado pelo novo vírus ocupava o mais alto grau de alerta dessa Organização, o da Emergência de Saúde Pública de Importância Internacional, finalmente classificando-o em 11 de março de 2020 como pandemia (Freitas; Napimoga; Donalisio, 2020). À medida que esta pandemia avançou pelo mundo, atingindo os países da América Latina, foram se tornando visíveis problemas estruturais, como os cortes e a falta de investimento na saúde pública e a carência de recursos sociais básicos para sustentação da vida (Caponi, 2020; Santos, 2020).

Algumas das principais estratégias de enfrentamento da pandemia têm se orientado por formas de distanciamento e isolamento social, a fim de coibir seu alastramento e favorecer atendimentos adequados àqueles que estão doentes, levando em conta a capacidade do sistema de saúde de suportar tal contingente. Todavia, em localidades em que as condições de vida são precárias, desde a falta de infraestrutura de saneamento básico e de serviços públicos, passando por moradias pequenas e insalubres, até a tensão de situações de violências, como as de gênero ou raça/etnia, muitas vezes associadas ao tráfico de drogas e seus embates com a polícia, há particularidades que colocam em xeque o modelo de isolamento social como estratégia sanitária de proteção à doença (ou à covid-19). Essas moradias abrigam muitas pessoas que, normalmente, não têm privacidade nem condições de se preservar de contatos sociais. Além disso, o distanciamento 
social, associado a curvas de contágio e avanço da epidemia, gera mudanças significativas no modo de vida das pessoas e impacta a economia. Tendo em vista que muitos desses indivíduos trabalham como prestadores de serviços e em atividades informais com baixa remuneração, essas situações são agravadas na pandemia - muitos, inclusive, perderam seus empregos e outros ainda dependem do auxílio emergencial (Aquino et al., 2020; Souza, 2020).

A pandemia persiste gerando angústia e incertezas, em meio à expectativa da vacina. Observamos a segunda onda em países europeus e aumento dos casos nos Estados Unidos. No Brasil, oscilamos entre uma certa estabilização, em patamares altos das curvas móveis, e a emergência de uma segunda onda. Após as eleições municipais, volta-se a reforçar medidas de distanciamento e isolamento social, restringindo-se a circulação de pessoas e situações que possam gerar aglomerações. São Paulo, por exemplo, encontra-se em fase emergencial. Em meio às incertezas e expectativas de melhoria, notamos que em territórios vulneráveis a rotina parece ser a mesma (Sakamoto, 2020). A situação, acirrada pela desconsideração do uso de máscaras, vigora suscitando um contexto complexo em que ações de prevenção são fragilizadas, tendo como uma das consequências a sobrecarga de profissionais de saúde, especialmente da atenção primária à saúde (Cataia, 2020; Lotta et al., 2020).

Desta forma, mostra-se urgente pensarmos formas de preservar a vida, a saúde e o trabalho dessas pessoas neste contexto de pandemia. Torna-se também urgente implementar políticas públicas que assegurem a vida das pessoas em vulnerabilidade e exclusão social, como a renda básica, a ampliação nos investimentos no Sistema Único de Saúde e suas capilaridades, como o Núcleo de Apoio à Saúde da Família, e a segurança pública, em especial para mulheres e crianças em situação de violência.
Assim, constatamos que a pandemia de covid-19 surge em uma economia global predominantemente neoliberal já desestabilizada e em intensa crise de legitimidade. A questão da pandemia nos surpreende por muitos motivos, pois afeta nossa visão de mundo, nossos hábitos e nossas expectativas de futuro. Será que ela suscitará mudanças mais profundas nos modos de sociabilidade, produção de conhecimento e de organização econômica e política? Destacar a pandemia neste contexto sobre as desigualdades em suas diferentes faces implica escancarar, a nosso ver, as consequências funestas de uma sociedade pós-colonial, em que a maioria das pessoas já vivia de modo precário antes da pandemia, o que se agravou, com poucas alternativas quanto a um enfrentamento da covid-19, especificamente quanto aos modos de prevenção (Mbembe, 2018).

Estas reflexões tomam corpo em atividades de pesquisas abrangentes realizadas em um bairro de alta vulnerabilidade da Baixada Santista, referenciadas pela pesquisa participante. Estas buscavam compreender as consequências da desigualdade social à luz das práticas de saúde, especialmente aquelas da atenção primária à saúde como desencadeadoras destas reflexões. Por sua vez, essas pesquisas tiveram como eixos teóricoconceituais a ética do cuidado ${ }^{2}$ e os processos de participação social. ${ }^{3}$ É importante destacar que o desenvolvimento e articulação entre estes eixos tem esteio hoje em um novo projeto em andamento, cujo objetivo geral é compreender os processos psicossociais de participação social a partir do acolhimento e cuidado dados por meio de práticas da Estratégia Saúde da Família desenvolvidas em contextos de exclusão social. ${ }^{4}$ Este dossiê é composto por artigos que trazem diferentes discussões associadas aos eixos de pesquisa. A questão da covid-19 está contemplada em um projeto em andamento, que possibilitou a atualização das informações no contexto da

\footnotetext{
2 "Ética do cuidado e construção de direitos: acolhimento psicossocial em práticas da saúde da família em situações de exclusão social" Fundação de Amparo à Pesquisa do Estado de São Paulo (Fapesp) nº 2016/23973-2.

3 "Desigualdade social e subjetividade: trajetórias de vida e lutas por melhores condições de vida e saúde em território vulnerável da Baixada Santista" - Conselho Nacional de Desenvolvimento Científico e Tecnológico (CNPq) nº 407836/2016-o.

4 "Ética do cuidado e processos psicossociais de participação social em práticas da saúde da família em situações de exclusão social" Bolsa Produtividade CNPq n ${ }^{0} 308730 / 2019-4$.
} 
pandemia. ${ }^{5}$ Assim, o objetivo principal deste dossiê é buscar interpretações possíveis sobre a relação entre saúde e sociedade, a partir da construção compartilhada e democrática do conhecimento em territórios marcados pela exclusão social, visando construir subsídios para a ampliação de políticas públicas de enfrentamento à desigualdade social, agravada durante a pandemia de covid-19.

Cabe lembrar que este editorial, tendo em vista que abrange práticas de saúde em um mesmo território, indica uma sintonia e complementações expressas nos artigos, os quais, por vezes, refletem o esforço de estruturação de uma mesma abordagem teóricoconceitual e metodológica. Desta forma, visando contribuir com a compreensão mais articulada dos artigos, este editorial traz uma caracterização do campo de práticas de pesquisa para situar melhor o leitor. Na sequência, traz algumas reflexões sobre o percurso teórico-metodológico que tem referenciado este grupo de pesquisa orientado pelas práticas do Laboratório de Estudos sobre a Desigualdade Social (Leds) e, por fim, uma breve descrição dos artigos contidos neste dossiê. Desejamos uma boa leitura!

\section{O contexto de um território de alta vulnerabilidade em Cubatão/SP}

A partir de práticas de ensino, pesquisa e extensão realizadas pela Universidade Federal de São Paulo (Unifesp) em Cubatão/SP, um caminho de práxis tem sido construído. Este conceito é entendido como a indissociabilidade entre teoria e prática, que promove uma ação consciente e crítica, inclusive conferindo ao pesquisador um papel político na transformação social (Furlan, 2019). Desta forma é vislumbrada a melhoria de condições de vida desta população por meio do enfrentamento das consequências da desigualdade social. Esta localidade é um bairro de alta vulnerabilidade e exclusão social, com graves casos de violências e adoecimentos, segundo dados do Índice Paulista de Vulnerabilidade Social (IPVS). Desde 2012 têm sido desenvolvidas pesquisas que consideram as práticas da atenção primária à saúde como desencadeadoras de diferentes temas associados com as determinações sociais do processo saúde-doença-cuidado.

É importante destacar que este território de alta vulnerabilidade, segundo dados do IPVS (Ferreira; Dini; Ferreira, 2006), está incluído no grupo 6, ou seja, vulnerabilidade muito alta - aglomerados subnormais, com 36.314 pessoas (31\% do total da população de Cubatão). No espaço ocupado por esses setores censitários, o rendimento nominal médio dos domicílios era de R\$̣ 1.o88, e em 32,2\% deles a renda não ultrapassa meio salário mínimo per capita. Com relação aos indicadores demográficos, a idade média dos responsáveis pelos domicílios era de 40 anos, e aqueles com menos de 30 anos representavam $23,5 \%$. Dentre as mulheres chefes de domicílios, $24,1 \%$ tinham até 30 anos, e a parcela de crianças com menos de 6 anos equivalia a 11,7\% do total da população desse grupo.

Os trabalhos de pesquisa realizados, referenciados pela pesquisa-participante, têm valorizado um olhar para a dinâmica comunitária, para o cuidado e para os vínculos afetivos e sociais como estratégia de apreensão das consequências da desigualdade social, neste território marcado por um histórico de lutas desde sua criação, por volta da década de 1950. Este histórico traz consigo traços de um estigma da cidade de Cubatão associado a um polo industrial importante, devido à exacerbação da poluição causadora de vários agravos à saúde (Ferreira-Filho, 2015). Após muitos anos, a situação hoje é marcada por mais um embate quanto à construção de cavas subaquáticas no mangue para despejo de lixo tóxico.

\section{Referências teórico-conceituais e ético-políticos}

A busca de referenciais teórico-conceituais tem sido um grande desafio para a compreensão dos fenômenos associados às consequências da desigualdade social por meio das práticas de saúde desenvolvidas neste território, alvo deste dossiê, e também em outros territórios vulneráveis da

\footnotetext{
5 "A participação social de lideranças comunitárias e a busca de melhoria das condições de vida: experiências de luta pela promoção de cidadania”, projeto de mestrado de Hailton Yagiu, sob a orientação do prof. dr. Carlos Roberto de Castro e Silva, vinculado ao Programa Interdisciplinar em Ciências da Saúde da Universidade Federal de São Paulo, Instituto Saúde e Sociedade.
} 
Baixada Santista nos quais são realizadas atividades de ensino, pesquisa e extensão (Silva et al., 2014a).

Partimos da proposta de que a complexidade do fenômeno estudado e sua práxis exigem a abertura de frentes de conhecimento e apreensão de um repertório que extrapole a singularidade de disciplinas estanques. Nesta busca, a interdisciplinaridade tem sido um caminho profícuo, inclusive respaldado pelo escopo do Programa de Pós-Graduação em que tais trabalhos têm sido desenvolvidos - o Programa Interdisciplinar de Ciências da Saúde da Unifesp. Inclusive, a produção dos artigos deste dossiê acontece com a colaboração de pesquisadores desse Programa e de diferentes áreas do conhecimento, particularmente das ciências humanas e sociais e da saúde coletiva, que assessoraram em momentos distintos o desenvolvimento dos projetos de pesquisa, assim como da participação em bancas de alunos da pós-graduação com temáticas relacionadas ao objeto principal deste dossiê.

Neste sentido, a compreensão da realidade de territórios marcados pela exclusão social suscita diferentes abordagens, que incluem dimensões sociais, culturais, políticas, econômicas e psicológicas. A visão materialista dialética e histórica propicia uma articulação entre essas dimensões, que enriquecem uma visão problematizadora das consequências da desigualdade social, inclusive porque valoriza aspectos estruturais geradores de tal situação no caso brasileiro, baseada nas heranças de uma sociedade escravocrata, racista, patriarcal e classista (Dussel, 200o; Lane; Codo, 2006; Martín-Baró, 2017).

Nesta linha, a psicologia sócio-histórica tem sido o principal esteio a partir do qual acontece este diálogo interdisciplinar. Essa perspectiva crítica da psicologia social tem possibilitado catalisar interesses em que a intersubjetividade passa a ser um eixo de compreensão da realidade. A partir de uma orientação do materialismo histórico-dialético, calcado principalmente em Vigotski, temos uma concepção de sujeito intrínseca à sua interação com o meio social (Lane; Codo, 2006; Sawaia, 2016). Além disso, segundo González Rey (2017), a subjetividade passa a ser problematizada no campo de produção do conhecimento, pois se constitui um lócus ao mesmo tempo epistemológico e metodológico de interpretação dos fenômenos sociais e simbólicos, os quais formam a cultura e suas diferentes expressões (Rossato; Martínez, 2018).

Nesta perspectiva, os estudos sobre a afetividade no campo da psicologia sócio-histórica desenvolvidos por Silvia Lane e Bader Sawaia têm fortalecido o papel da subjetividade nos estudos sobre o fenômeno da desigualdade social. A afetividade, na perspectiva materialista histórica e dialética, contribui, assim como as categorias da atividade, linguagem e consciência, para a compreensão do processo dialético da inclusão/exclusão social (Sawaia, 2001). Sawaia (2016), baseada em Espinosa e Vigotski, discute o processo da dialética da exclusão e inclusão social, que ilumina a compreensão de uma inclusão perversa, desencadeadora de um sofrimento que tem sua gênese em condições socioeconômicas e culturais excludentes. Por sua vez, a felicidade ético-política está associada a uma potência de ação, em referência na ética de Espinosa (1989), promotora de bons encontros.

Nesta linha podemos inferir a presença de um ciclo dos afetos que visa à potencialização do conatus, conceito de Espinosa (1989) definido como a perseverança na existência. Segundo Wagner (2015), para o filósofo, o conatus coletivo baliza as ações para o bem comum - inclusive, na teoria espinosana, especialmente no Tratado Teológico-Político (2019), há uma concepção do direito natural relacionado à potência de agir dos indivíduos. Isto é, mais do que leis baseadas em um contrato social, há uma afetação que suscita mudança de si e do outro, principalmente em situações em que a vida está em perigo, suscitando o exercício do direito à resistência. Nesse sentido, a noção de resistência, segundo Guimaraens e Rocha (2014), é vista como uma força que faz parte dessa potência voltada a perseverar na existência defendendo seus direitos, e não como uma atitude reativa ou debeladora da ordem.

Ancorados nessas referências, a politização da afetividade tem regido nosso olhar para a compreensão da qualidade dos vínculos estabelecidos nos territórios abordados, especialmente a partir da dinâmica de funcionamento das unidades de saúde da família em sua relação com a comunidade. Tal politização tem referenciado nossas reflexões e ações, pois potencializa e descobre no cotidiano novas possibilidades de socialização e transformação social pautadas pela cidadania e pelos direitos. 
Nesta linha, o cuidado se mostrou o principal esteio de apreensão de processos de politização da afetividade, pois evidencia a importância do vínculo para a formação de um ser humano feliz, saudável e cidadão - especialmente a ética do cuidado, como um campo que possibilita a problematização dos valores ético-morais que regem a convivência humana. Ferreira (1997), estudiosa de Espinosa, aborda a ética do cuidado por meio da valorização dos afetos como dimensão importante para o trabalho da própria razão.

O pensamento de Espinosa nos ajuda a compreender o papel dos desejos no impulso de vida dos sujeitos e de seu papel para a constituição da razão. A ideia não é estabelecer uma relação mecanicista entre razão e afeto, mas entender que o desejo, como coloca Ferreira (1997, p. 453), "reflete tudo o que acontece ao indivíduo. É ele que permite o relacionamento com as coisas, pois no seu expansionismo apela para elas. É o desejo que fundamenta a sociabilidade”.

Por sua vez, a valorização do cuidado subverte valores capitalistas em que o lucro prevalece sobre valores que aproximam e enriquecem os vínculos, como a solidariedade e o respeito. Este tipo de reflexão tem encontrado respaldo na ética do cuidado, especialmente de orientação feminista e interseccional, pois, ao valorizar a importância do cuidado na formulação de políticas públicas, problematizamos o papel da mulher em uma sociedade machista e preconceituosa (Keller; Kittay, 2017; Pintasilgo, 2011).

Esta perspectiva direciona para o que consideramos ser uma das principais vocações da Estratégia Saúde da Família, ou seja, propiciar uma apreensão do processo de saúde-doença e cuidado que não se restrinja aos aspectos biomédicos e/ou técnicos de sua atuação, sob a orientação do modelo cartesiano de produzir saúde. Destacamos o papel do agente comunitário de saúde (ACS) nesta discussão, pois desta forma ressignificamos o lugar de mediação que este ocupa entre unidade de saúde da família e comunidade - lugar nada confortável devido às exigências de uma população marcada por inúmeras demandas, das quais a saúde sozinha não dá conta nem deveria, porque depende da implementação de outros princípios do Sistema Único de Saúde (SUS), destacando a intersetorialidade, integralidade e participação social (Silva et al., 2014b).

Nas atividades desenvolvidas pela atenção primária à saúde nesse território, o convívio e a parceria dos ACS têm sido fundamentais, pois revelam ao mesmo tempo a fragilidade humana, a vulnerabilidade que nos torna humanos, como nos lembra Boff (2014), e, por outro lado, as potencialidades da amizade e da solidariedade.

Assim, os estudos realizados neste território nos têm desafiado a pensar o cuidado como uma ferramenta ético-política de transformação da realidade em contextos de exclusão social, pois esse cuidado, em muitas situações, tem sido desvalorizado ou serve a um papel de naturalização do sofrimento e subalternidade da mulher e do trabalhador de saúde.

\section{A questão do método e a construção da práxis}

A pesquisa participante, principal balizadora dos estudos realizados no território supracitado, tem sido objeto de muitas discussões e reflexões no Leds, pois é vista como um método importante para a construção de processos de transformação social, reforçando a proposta da psicologia sócio-histórica e cultural, interdisciplinar, em sua vertente crítica de desnaturalização e desideologização de fenômenos sociais (Martín-Baró, 2017).

Os estudos referenciados na pesquisa participante têm possibilitado uma discussão profícua sobre método, especialmente da pesquisa social comprometida com territórios marcados pela exclusão social. Nesta linha, a perspectiva ético-política tem apresentado desafios importantes, pois a construção de um processo de pesquisa nestes territórios envolvendo instituições, profissionais de saúde e lideranças comunitárias, entre outros, tem exigido negociações e redefinições constantes do papel de cada um. Pelo lado da universidade, vivemos um momento em que a produtividade acadêmica consome docentes e discentes por um maior número de artigos em contraposição à pouca valorização de projetos de extensão. Pelo lado dos serviços públicos de saúde, está em andamento um processo de desmonte do SUS, colocando os trabalhadores em situações de muito estresse e aumento das demandas, como a pandemia de covid-19 tem nos mostrado (Prado et al., 2020; Sarti et al., 2020). Por sua vez, as lideranças comunitárias se deparam com desafios trazidos pelo aumento da fome e da violência, que trazem mais para 
perto as lutas diárias voltadas para a sobrevivência. Desta forma, há necessidade de uma contextualização sócio-histórica e cultural de pesquisas de caráter participativo que nos aproxime da dura realidade atual de territórios marcados pelo aumento da fome, violência em suas diferentes faces e desemprego.

Assim sendo, temos buscado diferentes ferramentas de análise e discussão das informações obtidas no trabalho de campo, particularmente de referências que nos possibilitem uma maior riqueza de interpretações da realidade vivida por pessoas, grupos e comunidades.

A hermenêutica de profundidade (HP) tem sido a principal referência teórica, na medida que estrutura a análise em níveis que contextualizam sócio-histórica e culturalmente as falas dos sujeitos. O histórico da hermenêutica na trajetória das ciências sociais e humanas, especialmente a partir da segunda metade do século XX, particularmente com Gadamer (2015) e Ricoeur (2016), tem favorecido o fortalecimento de uma proposta de ciência que valoriza e dialoga com o singular.

A referência da HP propõe um nível de aprofundamento do discurso que permite o vislumbre de diferentes camadas da construção do universo simbólico e subjetivo. Além disso, como destaca Thompson (2011) na terceira e última etapa da análise denominada de interpretação/reinterpretação, há a valorização do posicionamento do pesquisador que traz novas discussões a partir da articulação entre as duas etapas anteriores, análise sócio-histórica e análise discursiva. Desta forma, ao mesmo tempo que o pesquisador traz novos pontos de vista sobre as questões tratadas, por outro lado se valoriza o discurso trazido pelos sujeitos da pesquisa, pois tais contribuições colaboram com a construção de verdades que não são estanques nem definitivas.

$\mathrm{Na}$ busca por aprimorar formas de processos de análise, temos ensaiado articulações entre os principais referenciais que orientam nossas pesquisas, inclusive oferecendo, especialmente ao jovem pesquisador, um leque maior de opções e combinações. Esta diversificação, acreditamos, tem favorecido mediações que enriquecem processos singulares e criativos interessantes de compreensão da realidade. Mandelbaum (2012), discutindo a possibilidade de diálogo sobre o método entre ciências humanas em geral e a psicologia social em particular, referenciada em Gadamer (2015), valoriza a qualidade da relação entre pesquisador e pesquisado. Segundo Gadamer (2015), compreender implica estabelecer um diálogo entre pesquisador e pesquisado, no qual haja um intercâmbio entre parceiros, sendo possível cada um destes colocar-se no lugar do outro, revelando assim sua humanidade intrínseca.

Nesta linha, a epistemologia qualitativa de González Rey (2011, p. 15) tem dialogado com este processo de análise da HP, à medida que a pesquisa é vista como

um espaço permanente de comunicação que terá um valor essencial para os processos de produção de sentido dos sujeitos pesquisados nos diferentes momentos de sua participação neste processo. A pessoa que participa da pesquisa não se expressará por causa de uma exigência instrumental externa a ela, mas por causa de uma necessidade pessoal que se desenvolverá, crescentemente, no próprio espaço da pesquisa, por meio dos diferentes sistemas de relação constituídos nesse processo.

Um dos desdobramentos das pesquisas foi a proposição de práticas que pudessem traduzir alguns dos resultados destas para a comunidade. Dessa forma, desenvolvemos ações de extensão, com o objetivo de fortalecer a construção de redes sociais de apoio entre os serviços de saúde e a comunidade, tendo as lideranças comunitárias e ACS como articuladores dessas ações. O projeto de extensão da Unifesp criado em 2015, denominado e atualizado na pandemia de covid-19 como "Participação social, subjetividade e cuidado: fortalecendo redes em territórios vulneráveis em tempos de pandemia da covid-19", vem continuamente se debruçando sobre as melhores estratégias de envolvimento destes e de novos atores sociais. Estes têm contribuído com uma maior aproximação entre as redes de cuidado, as práticas do serviço de saúde e as necessidades da comunidade, incrementando a problematização da construção de processos de participação social. Tais aspectos têm sido relevantes e desafiadores desta práxis, visto que se mostram ao mesmo tempo como ferramentas para transformações sociais e como grandes desafios em meio à fragmentação das forças locais. 


\section{Considerações finais}

Os artigos apresentados neste dossiê trazem ricas experiências e reflexões que podem contribuir com a construção de análises, discussões e, eventualmente, com a ampliação de políticas públicas, na busca de um cuidado ético-político no contexto sócio-histórico e interseccional brasileiro. Precisamos repensar as bases apoiadas no capitalismo neoliberal, com raízes num passado escravista, para enfrentar o cenário da pandemia e da pós-pandemia, compreendendo a complexidade das formas de prevenção de agravos à saúde, especialmente de elementos importantes das determinações sociais da saúde. A pandemia de covid-19 mostra-se como um eixo transversal, destacando potencialidades e fragilidades, expressas nos seguintes artigos:

(1) "Cuidado em território de exclusão social: covid-19 expõe marcas coloniais", no qual se busca compreender as facetas do cuidado pela análise de narrativas de munícipes e sob referenciais da ética do cuidado, da interseccionalidade e do ecofeminismo. Percebe-se que a pandemia veio acirrar as heranças coloniais pré-existentes e mostrar a importância do SUS e das articulações de mulheres como saída para alcançar um cuidado ético-político.

(2) "Participação social de lideranças comunitárias em um contexto de desigualdade social e no enfrentamento da pandemia da covid-19: um enfoque psicossocial", que objetiva compreender os elementos psicossociais da participação e o envolvimento político de lideranças comunitárias, analisando o papel dos processos de socialização na potencialização (ou não) de ações coletivas. As reflexões ainda são atualizadas pelas consequências da pandemia da covid-19 no território.

(3) "As vivências da violência em um território vulnerável e periférico", que tem como objetivo discutir a questão das violências de gênero presentes em território de alta vulnerabilidade na Baixada Santista, em Cubatão/SP, território de vulnerabilidade social, articulada com ações de cuidado exercidas anterior e concomitantemente ao contexto da pandemia da covid-19.

\section{Referências}

AQUINO, E. M. L. et al. Medidas de distanciamento social no controle da pandemia de covid-19: potenciais impactos e desafios no Brasil. Ciência \& Saúde Coletiva, Rio de Janeiro, v. 25, p. 2423-2446, 2020. Suplemento 1.

BOFF, L. Saber cuidar: ética do humano: compaixão pela terra. 20. ed. Petrópolis: Vozes, 2014.

CAPONI, S. Covid-19 no Brasil: entre o negacionismo e a razão neoliberal. Estudos Avançados, São Paulo, v. 34, n. 99, p. 209-224, 2020.

CATAIA, M. Civilização na encruzilhada:

globalização perversa, desigualdades socioespaciais e pandemia. Revista Tamoios, Rio de Janeiro, v. 16, n. 1, p. 232-245, 2020.

DUSSEL, E. Ética da libertação na idade da globalização e da exclusão. Petrópolis: Vozes, 2000.

ESPINOSA, B. Ética. São Paulo: Nova Cultural, 1989.

FERREIRA, M. L. R. A dinâmica da razão na filosofia de Espinosa. Lisboa: Fundação Calouste, 1997.

FERREIRA, M. P.; DINI, N. P.; FERREIRA, S. P. Espaços e dimensões da pobreza nos municípios do estado de São Paulo. São Paulo em Perspectiva, São Paulo, v. 20, n. 1, p. 5-17, 2006. Disponível em: <https://bit.ly/3uzoVgt>. Acesso em: 7 abr. 2012.

FERREIRA-FILHO, C. B. A (toxi)cidade de Cubatão: história ambiental, desastres tecnológicos e a construção do imaginário ambiental da cidade tóxica na década de 1980. 2015. Dissertação (Mestrado em História) - Universidade Estadual do Centro-Oeste, Irati, PR, 2015.

FREITAS, A. R. R.; NAPIMOGA, M.; DONALISIO, M. R. Análise da gravidade da pandemia de covid-19. Epidemiologia e Serviços de Saúde, Brasília, DF, v. 29, n. 2, e2020119, 2020.

FURLAN, V. A práxis na psicologia social comunitária e nas políticas públicas (ou sobre seu sentido político). Revista Gestão \& Políticas Públicas, São Paulo, v. 9, n. 1, p. 84-100, 2019.

GADAMER, H. Verdade e método. Petrópolis: Vozes, 2015.

GUIMARAENS, F.; ROCHA, M. Spinoza e o direito de resistência. Sequência, Florianópolis, n. 69, p. 183-213, 2014. 
KELLER, J.; KITTAY, E. F. Feminist ethics of care. In: GARRY, A.; KHADER, S. J.; STONE, A. (Ed.).

The Routledge companion to feminist philosophy. Abingdon: Routledge, 2017. p. 540-555.

LANE, S.; CODO, W. Psicologia social: o homem em movimento. Brasília, DF: Brasiliense, 2006.

LOTTA, G. et al. Community health workers reveal covid-19 disaster in Brazil. The Lancet, London, v. 396, n. 10248, p. 365-366, 2020.

MANDELBAUM, B. Em busca de um encontro: o método hermenêutico na pesquisa em psicologia social. Temas em Psicologia, Ribeirão Preto, v. 20, n. 1, p. 227-234, 2012.

MARTÍN-BARÓ, I. Crítica e libertação na psicologia: estudos psicossociais. Petrópolis: Vozes, 2017.

MBEMBE, A. Necropolítica: biopoder, soberania, estado de exceção, política da morte. São Paulo: N-1 Edições, 2018.

PINTASILGO, M. L. Para um novo paradigma: um mundo assente no cuidado: antologia de textos de Maria de Lourdes Pintasilgo. Porto: Afrontamento, 2011.

PRADO, A. D. et al. A saúde mental dos profissionais de saúde frente à pandemia do covid-19: uma revisão integrativa. Revista Eletrônica Acervo Saúde, São Paulo, e4128, 2020. Número especial 46.

REY, F. G. Pesquisa qualitativa em psicologia: caminhos e desafios. São Paulo: Cengage Learning, 2011.

RICOEUR, P. Teoria da interpretação: o discurso e o excesso de significação. Lisboa: Edições 70, 2016.

ROSSATO, M.; MARTÍNEZ, A. M. Contribuições da metodologia construtivo interpretativa na pesquisa sobre o desenvolvimento da subjetividade. Revista Lusófona de Educação, Lisboa, v. 40, n. 40, 2018.

SAKAMOTO, L. Mais pobres têm o dobro do risco de se infectarem com coronavírus no Brasil. Coluna UOL, São Paulo, 2020. Disponível em: $<$ https://bit.ly/3fTriXn>. Acesso em: 10 jan. 2021.

SANTOS, B. S. A cruel pedagogia do vírus. São Paulo: Boitempo, 2020.
SARTI, T. D. et al. Qual o papel da atenção primária à saúde diante da pandemia provocada pela covid-19? Epidemiologia e Serviços de Saúde, Brasília, DF, v. 29, n. 2, e2020166, 2020. Disponível em: <https://bit.ly/3s41Kt7>. Acesso em: 10 jan. 2021.

SAWAIA, B. As artimanhas da exclusão: análise psicossocial e ética da desigualdade social. São Paulo: Vozes, 2016.

SAWAIA, B. B. Participação social e subjetividade. In: SORRENTINO, M. (org.). Ambientalismo e participação na contemporaneidade. São Paulo: Educ/Fapesp, 2001. p. 115-134.

SILVA, C. R. C. et al. Extensão universitária e prática dos agentes comunitários de saúde: acolhimento e aprendizado cidadão. Saúde e Sociedade, São Paulo, v. 23, n. 2, p. 677-688, 2014 a.

SILVA, C. R. C. et al. Participação social e a potência do agente comunitário de saúde. Psicologia \& Sociedade, Belo Horizonte, v. 26, p. 113-123, 2014b. Número especial 2. Disponível em: <https://bit.ly/3dSbJwK>. Acesso em: 10 jan. 2021.

SOUZA, J. A gramática social da desigualdade brasileira. Revista Brasileira de Ciências Sociais, Brasília, DF, v. 19, n. 54, p. 79-96, 2004. Disponível em: <https://bit.ly/3dNZHEm>. Acesso em: 10 jan. 2021.

SOUZA, J. N. Covid-19 e capitalismo: uma visão. In: CASTRO, D.; DAL SENO, D.; POCHMANN, M. (Org.). Capitalismo e a covid-19: um debate urgente. São Paulo, 2020. p. 11-18. Disponível em: <https://bit.ly/39Tv53l>. Acesso em: 10 jan. 2021.

THOMPSON, J. B. Ideologia e cultura moderna: teoria social crítica na era dos meios de comunicação de massa. Petrópolis, RJ: Vozes, 2011.

WAGNER, C. W. B. G. W. O conatus coletivo e a democracia no tratado político de benedictus de Spinoza. Revista Seara Filosófica, Pelotas, n. 11, p. 59-76, 2015 .

\section{Contribuição dos autores}

Castro-Silva elaborou e redigiu os principais argumentos do texto. Forte contribuiu com a argumentação sobre a Hermenêutica e revisão da argumentação geral e de conceitos, e lanni contribuiu com a discussão e revisão dos argumentos e conceitos.

Recebido: 13/01/2021

Aprovado: 09/03/2021 